\title{
Radiographic Evaluation of Endodontic Treatment Performed by Undergraduate Students and Interns
}

\author{
Anam Fayyaz ${ }^{1}$ \\ BDS \\ Saroosh Ehsan ${ }^{2}$ \\ BDS, FCPS \\ Rida Fatima Waseem ${ }^{3}$ \\ BDS
}

OBJECTIVE: The objective of this study was to radiographically examine the endodontic treatment performed by final year undergraduate students and interns.

METHODOLOGY: Post-obturation periapical radiographs of teeth $(\mathrm{n}=120)$ were randomly selected for evaluation. The root canal treatment was performed by final year students under supervision (sixty teeth) and interns (sixty teeth) at FMH College of Medicine and Dentistry, Lahore. The criteria for assessment of the quality of root canal obturation included adequate length, density of root filling, taper, coronal seal and the absence of any procedural errors. The root canal obturations were categorized as acceptable or unacceptable. Frequency and percentage were computed for categorical variables like length of the root filling, taper of the root filling, density of the root filling, coronal seal and fractured instrument. Mean with standard deviation were computed for quantitative variable like designation of dentist. Chi-square test was used to report significant findings. Significance was set at $\mathrm{p}$ value of $<0.05$.

RESULTS: Among the final year students the percentages for adequate length, density, taper and coronal seal were $88.3 \%, 91.6 \%, 88.3 \%$ and $90 \%$ respectively in 60 teeth treated. Among the interns the percentage for adequate length, density, taper and coronal seal were $63.3 \%, 66.7 \%, 61.7 \%$ and $80 \%$ respectively.

CONCLUSIONS: The results demonstrated that the quality of root canal obturation was less than ideal in interns compared to final year students.

KEY WORDS: Root canal treatment, obturation, radiographic quality, undergraduates, interns

HOW TO CITE: Fayyaz A, Ehsan S, Waseem RF. Radiographic evaluation of endodontic treatment performed by undergraduate students and interns. J Pak Dent Assoc 2018;27(3):115-19.

DOI: https://doi.org/10.25301/JPDA.273.115

Received: 17 April 2018, Accepted: 18 May 2018

\section{INTRODUCTION}

$\mathrm{E}$ ndodontic therapy is one of the most commonly performed procedures in dental clinics. ${ }^{1}$ It is therefore essential for clinicians to be skilled in this modality of treatment. The success of root canal treatment is directly dependent upon the proper cleaning and shaping of the root canal, but the long-term prognosis of a root canal treated tooth is more dependent upon the quality of obturation. ${ }^{2}$ Teeth with adequate root canal fillings have a lower incidence of apical periodontitis hence this factor is very important in the longevity of root canal treated teeth. ${ }^{3,4}$ The success rate of primary endodontic therapy has been reported to be $73 \%-97 \% .^{5,6}$

1. Senior Demonstrator, Department of Operative Dentistry, Fatima Memorial College of Dentistry, Lahore.

2. Associate Professor, Department of Operative Dentistry, Fatima Memorial College of Dentistry, Lahore.

3. Final year Resident, Department of Operative Dentistry, Islamic International Dental Hospital, Islamabad.

Corresponding author: "Dr. Saroosh Ehsan”<sarooshehsan77@gmail.com >
Root canal therapy outcome is assessed by radiographic evaluation alone or in combination with clinical or histological evaluation. ${ }^{1}$ The technical quality of root canal treatment is determined by factors such as instrumentation, radiographic obturation level and density. ${ }^{7,8}$

The level of proficiency achieved by undergraduates in their preclinical and clinical years, under direct supervision of faculty, translates into clinical efficiency in later years of professional life. The refinement of the skill is done not only at the undergraduate level but even after graduation. After graduation dentists are expected to perform endodontic treatment independently. However, the decay of knowledge takes place when dentists are working without direct supervision, leading to a decline in the quality of treatment. The longevity of endodontic therapy is affected by a number of factors in which radiographic quality of root canal obturation is one. ${ }^{3}$

The technical quality of root canal treatment done by students and interns has been widely examined in different populations. ${ }^{1,2,9-11}$ The results showed high frequency of 
inadequately performed root canal therapies. The reasons for this are not clear but may be due to limited endodontic teaching that was carried out at undergraduate level, insufficient time allocated for clinical endodontics, teaching not carried out by specialist endodontists and a low faculty to student ratio. ${ }^{2,12}$

The aim of the present study was to radiographically examine the technical quality of endodontic treatment performed by the final year undergraduate students and recent dental graduates.

\section{METHODOLOGY}

A retrospective evaluation of the root canal obturations performed in the Operative Dentistry Department of the Fatima Memorial College of Dentistry, Lahore was conducted. Ethical approval was obtained from Institutional Review Board. Records from August 2015 to January 2016 were examined and assessed. A total of 120 periapical radiographs were included by non probability convenience sampling. Inclusion criteria consisted of patients with age 18 to 60 years, both genders, permanent single and multi-rooted teeth. Retreatment cases, cases with incompletely formed roots, fractured roots and poor quality radiographs were excluded. Patient information and all related information regarding the endodontic treatment was recorded on specially designed proforma.

All treatment steps were conducted under direct supervision of teaching staff of the department with average student to faculty ratio of 5:1; interns were under indirect supervision. Root canal preparation was done using step back technique using stainless steel K-files. 1\% sodium hypochlorite solution was used for irrigation. Cold lateral condensation with gutta percha was used as the obturation technique along with a calcium hydroxide based sealer. Coronal restoration was done using composite or amalgam. Referral to the supervisor was made for permanent coronal restoration. A periapical radiograph of root treated tooth was taken using parallax technique on standard radiographic film which were manually developed and fixed, and then mounted on black holders by the same radiologist.

All radiographs were examined by 2 examiners, final year post graduate residents, who filled a proforma unanimously. Radiographs were interpreted in a darkened room using an illuminated viewer box whilst mounted in a cardboard slit to block off ambient light emanating from the viewer.

The assessment of the quality of root canal obturation was evaluated according to the criteria of Barrieshi-Nusair et al., with 2 additional criteria: coronal seal and fractured instrument, as shown in Table $1 .^{2}$ Iatrogenic mistakes for example ledges, apical perforations, gouging, missed canals, apical transportation, root perforation, canal straightening and fractured instruments were also recorded. The criteria for overall adequacy of root fillings in this study were defined

Table 1: Criteria followed to record information from radiographs. ${ }^{2}$

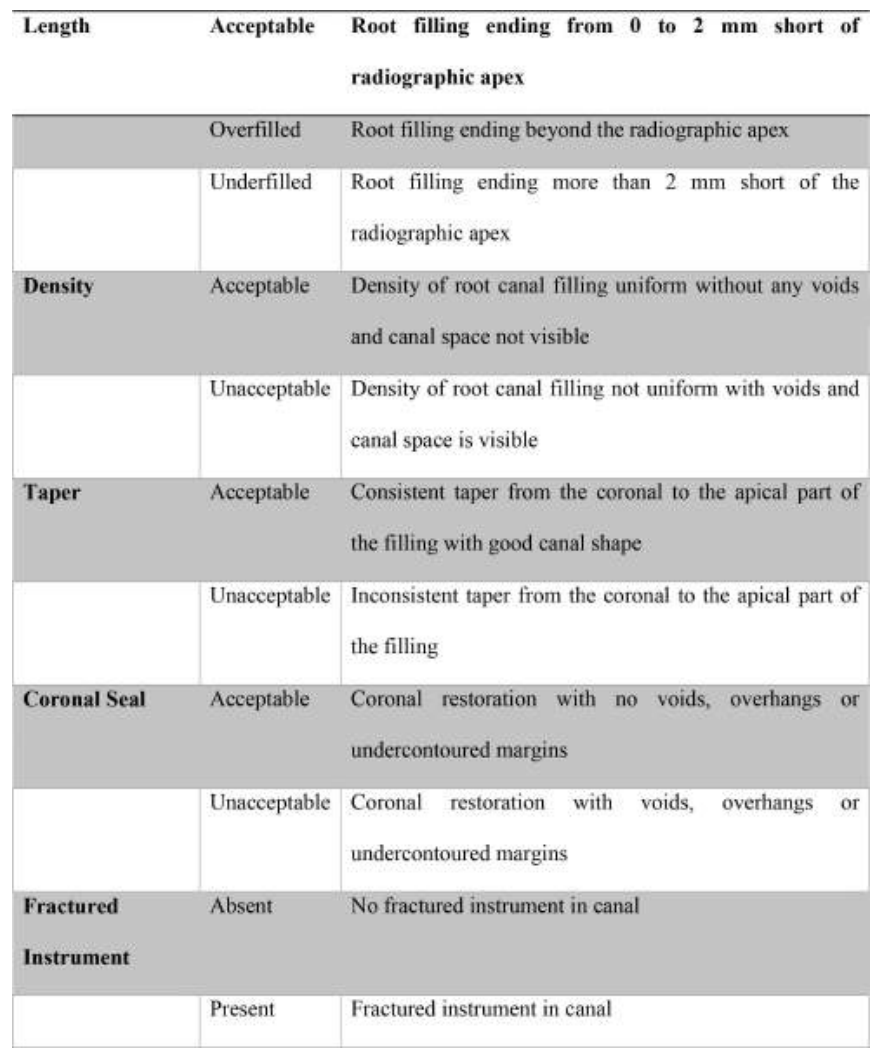

as the presence of adequate length, density, taper and absence of errors (ledge, fractured instrument, untreated canal, and apical transportation).

When both length and lateral seal of root filling were adequate the quality of root canal treatment was judged to be good. If either or both of the length and lateral seal of root filling were inadequate, the quality of treatment was assessed as poor.

Statistical analysis was carried out using SPSS 20. Frequency and percentage were computed for categorical variables like length of the root filling, taper of the root filling, density of the root filling, coronal seal and fractured instrument. Mean with standard deviation were computed for quantitative variable like designation of dentist. Chisquare test was used to report any significant finding. Significance was set at $\mathrm{p}$ value of $\leq 0.05$.

\section{RESULTS}

This study included 120 root filled teeth. Root canals were performed by final year students ( $\mathrm{n}=60$ teeth) and by 
interns ( $\mathrm{n}=60$ teeth). Total number of obturated canals were 207 with predominance of single rooted teeth, 55\%. Table 2 displays the characteristics of the teeth treated by both groups.

Table 2: Characteristics of the teeth $(n=120)$ treated by students and interns.

\begin{tabular}{|c|c|c|c|c|}
\hline Operators & $\begin{array}{l}\text { Maxillary } \\
\text { Anterior }\end{array}$ & $\begin{array}{l}\text { Maxillary } \\
\text { Posterior }\end{array}$ & $\begin{array}{l}\text { Mandibular } \\
\text { Anterior }\end{array}$ & $\begin{array}{l}\text { Maxillary } \\
\text { Posterior }\end{array}$ \\
\hline $\begin{array}{c}\text { Final year } \\
\text { students }\end{array}$ & 21 & 14 & 13 & 12 \\
\hline Interns & 7 & 20 & 9 & 24 \\
\hline
\end{tabular}

Table 3:Technical quality of obturation done by final year students and interns.

\begin{tabular}{|l|l|l|l|}
\hline & & final year students $(\mathrm{n}=60)$ & $\begin{array}{l}\text { interns } \\
(\mathrm{n}-60)\end{array}$ \\
\hline Length & acceptable & $88.33 \%(53)$ & $63.33 \%(38)$ \\
\hline & overfilled & $1.67 \%(1)$ & $10 \%(6)$ \\
\hline & underfilled & $10 \%(6)$ & $26.67 \%(16)$ \\
\hline density & acceptable & $91.67 \%(55)$ & $66.67 \%(40)$ \\
\hline & unacceptable & $8.33 \%(5)$ & $33.33 \%(20)$ \\
\hline taper & acceptable & $88.33 \%(53)$ & $61.67 \%(37)$ \\
\hline & unacceptable & $11.67 \%(7)$ & $38.33 \%(23)$ \\
\hline
\end{tabular}

Table 3 gives in detail the length, density, taper and coronal seal achieved by final year students and interns, respectively.

When individual canals were accounted for, it was found that final year students treated a total of 74 canals, of which $47(63.5 \%)$ were treated adequately and $27(36.5 \%)$ were inadequately treated. Whereas the total number of canals treated by interns were 133, of which 85 (63.9\%) were treated adequately and $48(36.1 \%)$ were inadequately treated. Therefore a total of $132(63.77 \%)$ of canals were treated adequately.

A significant finding was that final year students mainly performed root canals in the anterior sextant whereas interns performed root canal therapy in the posterior sextant $(\mathrm{p}=0.001)$.

Adequate length of obturation of root canal filling were significantly higher in those teeth which were treated by final year students than interns (Chi-Square $=10.59, \mathrm{p}=0.005$ ). Adequate density of obturation of root canal filling were significantly higher in those teeth which were treated by final year students than interns (Chi-Square $=11.37, \mathrm{p}=0.001$ ). Adequate taper of obturation of root canal filling were significantly higher in those teeth which were treated by final year students than interns (Chi-Square $=11.39, \mathrm{p}=0.001$ ). No statistical significant association was observed between groups in the coronal seal created (Chi-Square $=1.56$, $\mathrm{p}=0.21$ ).

Other findings were that 6 final year students created ledges whereas only 4 interns had ledges in the root canal treated tooth. One student had apical perforation in a root canal treated tooth whereas none of the interns had this preparation error. $4(6.7 \%)$ interns had caused gouging of their preparations whereas none of the students had this error in their preparations. This finding was statistically significant. $(\mathrm{p}=0.042)$.

A single student had apical transportation in the treated tooth whereas none of the interns caused this preparation error. None of the operators caused root perforation. Canal straightening was seen in no final year case but in 1 interns case. A single final year student had a missed canal whereas two interns had missed a canal. One final year student and 3 interns had a fractured instrument in a root canal treated tooth.

\section{DISCUSSIONS}

The technical quality of root obturation is an important indicator of the prognosis of an endodontically treated tooth. This key skill is taught to the dental students in their final year of undergraduate clinical training. Many authors believe that the techniques and practices learned during this period are carried forward in later profssional life. Therefore there is a need to assess the adequacy of the skill taught to undergraduate students and their ability to carry it forward as unsupervised interns.

The aim of this study was to compare the technical quality of the root canal obturation carried out by undergraduate students and interns at the department of Operative dentistry, Fatima Memorial Hospital, Lahore. The quality was assessed using routine postoperative radiographs in accordance with the criteria of BarrieshiNusair et al. ${ }^{2}$

The technical quality assessed by Rafeek et al. in dental students of Australia, reported $63 \%, 27.6 \%$ and $72.2 \%$ of obturations to have adequate length, density and taper respectively whereas overall acceptability of root fillings having adequate length and taper, absence of voids and no fractured instrument was found to be in $10.9 \%$ of the canals. 8 Their results were inferior as compared to our study where the undergraduates obturated with adequate length, density and taper in $88.3 \%, 91.6 \%$ and $88.3 \%$ of the obturations respectively. ${ }^{15}$

We found in our study, the percentage of root canal 
treatments carried out by final year undergraduates that were adequate in length, overfilled and under-filled were $88.33 \%$, $1.67 \%$ and $10 \%$, respectively and those performed by interns were $63.33 \%, 10 \%$ and $26.67 \%$, respectively. A study conducted by Barrieshi-Nusair et al. stated that $47.4 \%$ of teeth were adequately treated by undergraduates in Jordan. ${ }^{2}$ They found $61 \%$ teeth had acceptable root fillings in length, $4.2 \%$ were overfilled and $34.5 \%$ were under-filled in teeth treated by them. This is in accordance to our study. A higher percentage of adequately filled teeth in length were found in our study as compared to theirs. This difference may be due to strict supervision carried out by the faculty in the department. The supervisors ensure that students take multiple radiographs till adequate working length is achieved resulting in a higher percentage of adequate length compared to interns. Hayes et al. found that only $13 \%$ of teeth were adequately obturated by students. ${ }^{13}$ Our results are not in accordance to this study we report a higher percentage of adequately treated teeth. This can be accounted by the fact that only adequate obturations were accepted by the faculty for the undergraduate students and imperfections were asked to be corrected. The interns self-evaluated their obturations which resulted in the lesser percentage of adequately filled canals.

A study conducted by Ahmed et al. took interns into consideration and evaluated their obturated teeth. ${ }^{10}$ They concluded that $45 \%$ of teeth were adequately treated according to length and $73.3 \%$ had adequate density. In their study, 5 teeth had a fractured instrument in the canal. When compared to this study we observed that in our study, interns performed better by obturating to length adequately in $63.33 \%$ cases but did not perform as well when density was considered, only $66.67 \%$ had adequate density. Interns in our study had only 3 teeth with fractured instrument. The difference in density could be due to the increased level of difficulty in multirooted teeth. ${ }^{16}$

The undergraduate program includes preclinical and clinical endodontics in the third year and final year of the program. In the preclinical training the students are asked to perform endodontics on extracted teeth. In final year the students have a 2 month clinical rotation in which they are asked to perform root canal treatment on single rooted teeth under complete supervision of the faculty. The interns in the department are asked to perform at least 30 obturations in the department and report them in their logbooks to be signed by the faculty.

They are given need based supervision and help by the graduate dentists or postgraduate residents working in the department. However, their work is not evaluated at each step.

There is requirement of new protocols of assessment to be implemented by teaching dental hospitals for improvement in the performance of interns.

After graduation a dentist depends first and foremost on their self-evaluation. ${ }^{17}$ It is important therefore to develop a skill for self-evaluation in these emerging professionals. They should be able to recognise and correct their shortcomings. They should be encouraged to continue educating and training themselves to become better professionals than the ones that left their final year class. Limitations of the study were the small sample size, unequal distribution of types of teeth and using conventional periapical radiograph instead of digital periapicals, the examiners were not calibrated or standardized. The students and interns used the bisecting angle technique to take radiographs instead of paralleling technique which is reported in other studies. ${ }^{18}$

\section{CONCLUSIONS}

The technical quality of root canal treatment performed by undergraduate dental students was judged to be better as compared to interns. Thus, there is need to improve the quality of the root canal obturation performed by interns through revision of preclinical and clinical education in Endodontics and more vigilant clinical supervision.

\section{CONFLICT OF INTEREST}

None declared.

\section{REFERENCES}

1. Moradi S, Gharechahi M. Quality of root canal obturation performed by senior undergraduate dental students. Iranian Endo J. 2014; 9(1): 66-70.

2. Barrieshi-Nusair KM, Al-Omari MA, Al-Hiyasat AS. Radiographic technical quality of root canal treatment performed by dental students at the dental teaching center in Jordan. J Dent. 2004; 32(4):301-7. https://doi.org/10.1016/j.jdent.2004.01.002

3. Boucher Y, Matossian L, Rilliard F, Machtou P. Radiographic evaluation of the prevalence and technical quality of root canal treatment in a French Subpopulation. Int Endod J. 2002; 35(3): 229-38. https://doi.org/10.1046/j.1365-2591.2002.00469.x

4. Ertas ET, Ertas H, Sisman Y, Sagsen B, Er O. Radiographic assessment of the technical quality and periapical health of root-filled teeth performed by general practitioners in a Turkish Subpopulation. Sci World J.. 2013;2013:514841. doi:10.1155/2013/514841. https://doi.org/10.1155/2013/514841

5. Salehrabi R, Rotstein I. Endodontic Treatment outcomes in a large patient population in the USA: An Epidemiological Study. J Endod. 2004; 30(12):846-50.

https://doi.org/10.1097/01.don.0000145031.04236.ca 
6. Cheung GS. Survival of First-time Non-surgical root canal treatment performed in a dental teaching hospital. Oral Surg Oral Med Oral Pathol Oral Radiol Endod. 2002; 93(5):596-604. https://doi.org/10.1067/moe.2002.120254

7. Ng YL, Mann V, Gulabivala K. Tooth survival following nonsurgical root canal treatment: A systematic review of the literature. Int Endod J. 2010; 43(3)171-89.

https://doi.org/10.1111/j.1365-2591.2009.01671.x

8. Chugal NM, Clive JM, Spångberg LSW. Endodontic infection: Some biologic and treatment factors associated with outcome. Oral Surg Oral Med Oral Path Oral Rad Endod. 2003; 96(1):81-90. https://doi.org/10.1016/S1079-2104(02)91703-8

9. Hayes SJ, Gibson M, Hammond M, Bryant ST, Dumme PMH. An audit of root canal treatment performed by undergraduate students. Int Endod J. 2001;34(7):501-5

https://doi.org/10.1046/j.1365-2591.2001.00421.x

10. Ahmed A, Khattak O, Ali H, Maqbool I, Shahnawaz A, Azhar G, Shamim A. radiographic technical quality of root canal fillings performed by interns in the Islamic International Dental College: a pilot study. Pak Oral Dent J.1 2008; 28:271-4.

11. Rafeek RN, Smith WA, Mankee MS, Coldero LG. Radiographic evaluation of the technical quality of root canal fillings performed by dental students. Aust Endod J. 2012; 38:64-9. https://doi.org/10.1111/j.1747-4477.2010.00270.x
12. Dummer PM. Comparison of undergraduate endodontic teaching programmes in the United Kingdom and in some dental schools in Europe and the United States. Int Endod J 1991;24:169-77. https://doi.org/10.1111/j.1365-2591.1991.tb00127.x

13. Jethwani GS, Verma K, Sayed SS, Jethwani J. Endodontics by Emerging Dentists. J Ind Assoc Pub Health Dent 2011; 18:934-8.

14. Enabulele JE, Itimi E. Endodontic radiology, practice, and knowledge of radiation biology, hazard, and protection among clinical dental students and interns. Saudi Endod J 2015;3:171-6.

https://doi.org/10.4103/1658-5984.163634

15. Nagaraja S. Quality of root canal obturation performed by senior undergraduate dental students. Int J Pub Health Sci. 2015;3:197-200. https://doi.org/10.11591/.v4i3.4733

16. Jamleh A, Alfouzan K, Awawdeh L, Alfadley A, Ibrahim N, Alhijji S, Masuadi E. Successive spreader insertion forces induced by undergraduate students during canal obturation. Saudi Endod J 2017;7:110-4

17. Ray M, Milston A, Doherty P, Crean J. How Prepared are foundation dentists for independent genereal practice at 40 weeks of foundation training? Faculty Dent J 2018;1:30-38

https://doi.org/10.1308/rcsfdj.2018.30

18. Saatchi M, Mohammadi G, Sichani AV, Moshkforoush S. Technical quality of root canal treatment performed by Undergraduate clinical students of Ifshan Dental School. Iranian Endod J 2018; 1:30-36 